\title{
Lactate is Associated with Increased 30-Day Mortality in Critically III Patients with Alcohol Use Disorder
}

\author{
Yu Chen (iD) \\ Yuanyuan $\mathrm{Du}^{2}$ \\ Cheng Sun' \\ Wenliang Tan' \\ 'Department of Cardiology, Guangzhou \\ First People's Hospital, School of \\ Medicine, South China University of \\ Technology, Guangzhou, People's \\ Republic of China; ${ }^{2}$ Nursing School, \\ Peking University, Beijing, People's \\ Republic of China
}

Purpose: To investigate the predictive value of lactate for prognosis in critically ill patients with AUD.

Methods: A retrospective cohort study was performed using data extracted from a freely accessible critical care database (MIMIC-III). We studied all patients with AUD from the database for whom lactate was available. The clinical outcomes were 30-day mortality. Analyses included LOWESS curve fitting, logistic multivariate regression model, receiver operating characteristic (ROC) analysis and subgroup analysis.

Results: A total of 1296 eligible critically ill patients with AUD were included and there were 223 non-survivors (17.2\%). The non-survivors had a higher lactate than the survivors ( $p$ $<0.001$ ). A nonlinear relationship between lactate and 30-day mortality was observed. Multivariate logistic regression indicated lactate could be an independent risk factors to predict the prognosis of critically ill patients with AUD. According to ROC curve analysis, the area under the curve predicted by lactate for 30-day mortality was 0.672 (95\% CI, 0.634 to 0.711 ). Subgroup analysis did not find obvious interaction in most subgroups.

Conclusion: High lactate was associated with increased mortality in critically ill patients with AUD.

Keywords: alcohol use disorder, critically ill patients, lactate, mortality

\section{Introduction}

Alcohol consumption is the seventh leading risk factor for both death and disability-adjusted life years, which exerts considerable impacts on the health of patients and poses a huge socioeconomic burden. ${ }^{1}$ Alcohol use disorder (AUD) is a prevalent substance use disorder associated with various comorbidities, including liver disease, coronary artery disease, kidney disorders, pancreatitis, cancer, pneumonia, and stroke. ${ }^{2-5}$ The estimated number of people with AUD globally is 76.3 million, and the disorder accounts for 1.8 million deaths annually. ${ }^{6}$ Previous studies have reported that AUD presents in one-third of patients admitted to hospital intensive care units (ICUs), and that it is associated with the doubling of hospital mortality. ${ }^{7,8}$ Because of the high incidence of poor prognosis of critically ill patients with AUD, identifying effective and convenient prognostic predictors could be beneficial for doctors in the identification of patients at high risk and take timely interventions.

Lactate is a by-product of anaerobic metabolism and it has been regarded as a marker of tissue hypoperfusion and cellular hypoxia. ${ }^{9}$ Lactate was recently
Correspondence: Wenliang Tan Department of Cardiology, Guangzhou First People's Hospital, School of Medicine, South China University of Technology, Guangzhou, 510000,

Guangdong Province, People's Republic of China

Email 13570293370@I39.com 
identified as a key predictor of organ dysfunction and mortality in critically ill patients. ${ }^{10}$

However, an elevated serum lactate level may be due to impaired lactate clearance and/or excess production in the setting of alcohol consumption. ${ }^{11,12}$ It is unclear whether an elevated serum lactate level is also associated with outcome in critically ill patients with AUD. Consequently, the purpose of the present study was to explore the relationship between lactate levels and outcomes of critically ill patients with AUD.

\section{Methods}

\section{Data Source}

Data used in the present study were obtained from a publicly available critical care database called the Medical Information Mart for Intensive Care III (MIMICIII, version 1.4), which is a large, single-center database, with information for more than 40,000 critical care patients admitted to Beth Israel Deaconess Medical Center (Boston, MA, USA) from 2001 to 2012. ${ }^{13}$ To access the database, we completed the National Institutes of Health online course and passed the Examination for Protecting Human Research Participants (certification number 30110377). All data are de-identified in this database to protect patients' information and the requirement for individual patient consent is not indispensable.

\section{Study Population}

We selected adult patients ( $\geq 18$ years) with AUD who remained in ICU for more than 48 hours on their first admission. AUD was determined according to the Ninth Revision of the International Classification of Diseases; codes (291.X, 291.XX, 303.XX, 303.XX, 305.XX, $535.3 X, 357.5,425.5$, and 571.0 to 571.3, where $\mathrm{X}$ stands for wildcards). Patients were excluded if they met the following criteria: had no serum lactate data within the first 24 hours of admission; more than 5\% individual data were missing.

\section{Data Extraction}

Clinical data, including demographic parameters, vital signs, comorbidities, laboratory parameters, and scoring systems, were extracted from the database using structured query language (SQL) with pgAdmin4 PostgreSQL 10. The following data for comorbidities were extracted: congestive heart failure, atrial fibrillation, liver disease, sepsis, malignancy, respiratory failure, and renal failure.
Laboratory measurements included bicarbonate, creatinine, glucose, white blood cells (WBC), hemoglobin, platelets, anion gap, and prothrombin time (PT). Data for sequential organ failure assessment (SOFA) and the simplified acute physiology score II (SAPS-II) were also extracted. The other extracted data included demographic parameters (age, gender, and ethnicity), vital signs (systolic blood pressure [SBP], respiratory and heart rates), vasoactive drug use, and length of stay in the ICU. The clinical endpoint was 30-day mortality. The survival information was obtained from Social Security Death Index records. Baseline data were extracted within 24 hours after ICU admission.

\section{Statistical Analysis}

Baseline characteristics of all patients were stratified by lactate tertiles. Continuous variables were expressed as medians (interquartile ranges [IQR]) and compared using Kruskal-Wallis test or Mann-Whitney $U$-test. Categorical variables were expressed as percentages and compared using the Chi-square test. LOWESS smooth fitting was used to explore the crude relationship between lactate levels and mortality. We performed multivariate logistic regression analyses to determine whether lactate level was independently associated with 30-day mortality and the results were presented as odds ratios (ORs) with 95\% confidence intervals (CIs).

For the study outcome, we developed two multivariate models based on the lactate groups. In model I, covariates were adjusted only for age, ethnicity, and gender. In model II, covariates were adjusted for age, ethnicity, gender, creatinine, hemoglobin, platelet count, anion gap, bicarbonate, WBC count, respiratory rate, SBP, SAPS-II, atrial fibrillation, renal disease, liver disease, sepsis, respiratory failure, and vasoactive agent. The confounders selected in our models were based on their association with outcome in an effect estimate exceeding $5 \%$ or clinical judgement.

To further assess the prognosis value of lactate, we performed receiver operating characteristic curve analysis and calculated the area under the curve. In addition, we conducted stratification analyses to investigate whether the effect of lactate differed across various subgroups, including gender, ethnicity, congestive heart failure, atrial fibrillation, renal disease, liver disease, sepsis, malignancy, respiratory failure, and vasoactive drug use.

The data were analyzed using the STATA software (15.0) version and the EmpowerStats version 2.17.8 
(http://www.empowerstats.net/cn/). $\mathrm{P}<0.05$ was considered statistically significant.

\section{Results}

\section{Baseline Characteristics}

Based on the selection criteria, 1296 patients with AUD were included in the present study. We observed significant differences between the 30-day survivors and nonsurvivors (Table 1). A total of 223 patients died 30 days after admission in ICU and the mortality rate was $17.2 \%$. The patients included 976 males and 320 females with a mean age of 53.2 years. Non-survivors were significantly older than survivors (57.6 [48.8-68] vs 52.6 [43.4-61.2], respectively; $\mathrm{p}<0.001)$. Moreover, non-survivors had significantly higher SOFA and SAPS-II values than survivors (9 [6-12] vs 5 [3-7], $\mathrm{p}<0.001,49$ [40-58] vs 33 [25-42], respectively; $p<0.001$ ). In addition, survivors were less likely to have renal disease, atrial fibrillation, liver disease, sepsis, and respiratory failure, whereas non-survivors were more likely to use vasoactive drugs. Significant differences were observed in WBC count, creatinine, lactate, platelet count, bicarbonate, anion gap, hemoglobin, PT, respiratory rate, and SBP between survivors and non-survivors.

\section{Comparison Based on Lactate Level Tertiles}

The patients were divided into three groups based on lactate tertiles and the baseline characteristics are listed in Table 2 (group A: lactate $<1.3$; group B: $1.3 \leq$ lactate $<$ 2; group C: lactate $\geq 2$; Table 2). Patients with high lactate levels were more likely to have a history of acute kidney injury, liver disease, and sepsis; the patients also had high levels of bicarbonate, anion gap, creatinine, glucose, platelet count, PT, heart rate, SOFA, SAPS-II, and mortality.

\section{Relationship Between Lactate and Study Outcome}

We conducted LOWESS curve fitting to determine whether there was a linear relationship between 30-day mortality and lactate levels (Figure 1). No "U-shaped" relationship was observed from the curve.

In univariate and multivariate analyses, lactate was stratified by tertiles to determine whether lactate was independently associated with all-caused mortality (Table 3 ). The adjusted variables in each model are presented below Table 3
Table I Baseline Characteristics of Critically III Patients with AUD

\begin{tabular}{|c|c|c|c|}
\hline & Survivors & $\begin{array}{l}\text { Non- } \\
\text { Survivors }\end{array}$ & $\mathbf{P}$ \\
\hline Clinical parameters & 1073 & 223 & \\
\hline Age, years & $\begin{array}{l}52.6(43.4- \\
61.2)\end{array}$ & $57.6(48.8-68)$ & $<0.001$ \\
\hline Gender, $\mathrm{n}(\%)$ & & & 0.873 \\
\hline Female & $264(24.6)$ & $56(25.1)$ & \\
\hline Male & $809(75.4)$ & 167 (74.9) & \\
\hline Ethnicity, n(\%) & & & 0.081 \\
\hline White & $768(71.6)$ & $155(69.5)$ & \\
\hline Black & $82(7.6)$ & $10(4.5)$ & \\
\hline Other & $223(20.8)$ & $58(26)$ & \\
\hline $\mathrm{SBP}, \mathrm{mmHg}$ & $\begin{array}{l}\text { II9.9 (108.I- } \\
\text { II3.7) }\end{array}$ & $\begin{array}{l}109.8(100.3- \\
124.6)\end{array}$ & $<0.001$ \\
\hline Heart rate, beats/min & $\begin{array}{l}91.5(80.9- \\
103.8)\end{array}$ & $\begin{array}{l}92.2(81.2- \\
105.7)\end{array}$ & 0.651 \\
\hline $\begin{array}{l}\text { Respiratory rate, } \\
\text { beats/min }\end{array}$ & $\begin{array}{l}18.7(16.3- \\
21.7)\end{array}$ & $20(17.2-23.8)$ & $<0.001$ \\
\hline \multicolumn{4}{|l|}{ Laboratory parameters } \\
\hline Lactate & $1.5(I . I-2.2)$ & $2.1(1.5-3.2)$ & $<0.001$ \\
\hline Bicarbonate, $\mathrm{mmol} / \mathrm{L}$ & $21(18-24)$ & $19(15-22)$ & $<0.001$ \\
\hline Anion gap, mmol/L & $12(11-14)$ & $14(12-17)$ & $<0.001$ \\
\hline Creatinine, mg/L & $0.8(0.6-1.1)$ & I.I (0.8-I.9) & $<0.001$ \\
\hline Glucose, mg/dl & $104(89-123)$ & $104(83-125)$ & 0.427 \\
\hline WBC, $10^{9} / \mathrm{L}$ & $9(6.1-12.1)$ & $10(6-15.9)$ & 0.005 \\
\hline Hemoglobin, g/dl & $10.3(8.8-12)$ & $9.7(8.2-11.2)$ & 0.002 \\
\hline Platelet, $10^{9} / \mathrm{L}$ & $152(98-2 \mid 5)$ & $10 \mid(55-187)$ & $<0.001$ \\
\hline PT, second & $\begin{array}{l}13.6(12.6- \\
15.1)\end{array}$ & $\begin{array}{l}15.9(13.8- \\
19.8)\end{array}$ & $<0.001$ \\
\hline \multicolumn{4}{|l|}{ Comorbidities, n\% } \\
\hline $\begin{array}{l}\text { Congestive heart } \\
\text { failure }\end{array}$ & $80(7.5)$ & $15(6.7)$ & 0.704 \\
\hline Atrial fibrillation & $14 \mid(13.1)$ & $50(22.4)$ & 0.001 \\
\hline Renal disease & $57(5.3)$ & $26(11.7)$ & $<0.001$ \\
\hline Liver disease & $325(30.3)$ & $145(65.0)$ & $<0.001$ \\
\hline Respiratory failure & $519(48.4)$ & 151 (67.7) & $<0.001$ \\
\hline Malignancy & $113(10.5)$ & $27(12.1)$ & 0.49 \\
\hline Sepsis & $229(21.3)$ & $106(47.5)$ & $<0.001$ \\
\hline \multicolumn{4}{|l|}{ Scoring systems } \\
\hline SOFA & $5(3-7)$ & $9(6-12)$ & $<0.001$ \\
\hline SAPS-II & $32(25-42)$ & $49(40-58)$ & $<0.001$ \\
\hline $\begin{array}{l}\text { Vasoactive drug use, } \\
\mathrm{n} \%\end{array}$ & $367(34.2)$ & $139(62.3)$ & $<0.001$ \\
\hline $\begin{array}{l}\text { Length of ICU stay, } \\
\text { days }\end{array}$ & $5.2(3-10.1)$ & $5.8(3.5-10.2)$ & 0.213 \\
\hline
\end{tabular}

Abbreviations: AUD, alcohol use disorder; ICU, intensive care unit; SBP, systolic blood pressure; WBC, white blood cell; PT, prothrombin time; SOFA, sequential organ failure assessment; SAPS II, simplified acute physiology score II. 
Table 2 Baseline Characteristics of the Study Population with Different Lactate Level

\begin{tabular}{|c|c|c|c|c|}
\hline & & Lactate $(\mathrm{mmol} / \mathrm{l})$ & & \\
\hline \multirow[t]{2}{*}{ Characteristics } & Tertile I $(n=432)$ & Tertile $2(n=432)$ & Tertile $3(n=432)$ & $\mathbf{P}$ \\
\hline & Lactate $<1.3$ & $1.3 \leq$ Lactate $<2$ & Lactate $\geqq 2$ & value \\
\hline Age, years & $53.6(44.5-62.3)$ & $53.9(45.5-63.1)$ & $52(42.9-61)$ & 0.068 \\
\hline $\begin{array}{l}\text { Gender, } \mathrm{n}(\%) \\
\text { Female } \\
\text { Male }\end{array}$ & $\begin{array}{l}\text { I I0 (25.5) } \\
322(74.5)\end{array}$ & $\begin{array}{l}107(24.8) \\
325(75.2)\end{array}$ & $\begin{array}{l}103(23.8) \\
329(76.2)\end{array}$ & 0.858 \\
\hline $\begin{array}{l}\text { Ethnicity, n(\%) } \\
\text { White } \\
\text { Black } \\
\text { Other }\end{array}$ & $\begin{array}{l}315(72.9) \\
33(7.6) \\
84(19.5)\end{array}$ & $\begin{array}{l}311(72) \\
29(6.7) \\
92(21.3)\end{array}$ & $\begin{array}{l}298(69) \\
30(6.9) \\
104(24.1)\end{array}$ & 0.563 \\
\hline $\begin{array}{l}\mathrm{SBP}, \mathrm{mmHg} \\
\text { Heart rate, beats/min } \\
\text { Respiratoryrate, beats/min }\end{array}$ & $\begin{array}{l}119(107.3-133.4) \\
89.7(79.9-102.6) \\
18.8(16.4-21.6)\end{array}$ & $\begin{array}{l}117.8(107.1-131.4) \\
91.7(81.2-103.7) \\
18.8(16.4-22)\end{array}$ & $\begin{array}{l}119.5(106.1-132) \\
91.7(81.2-103.7) \\
19.2(16.5-22.6)\end{array}$ & $\begin{array}{l}0.515 \\
0.005 \\
0.430\end{array}$ \\
\hline $\begin{array}{l}\text { Laboratory parameters } \\
\text { Bicarbonate, } \mathrm{mmol} / \mathrm{L} \\
\text { Anion gap, } \mathrm{mmol} / \mathrm{L} \\
\text { Creatinine, } \mathrm{mg} / \mathrm{L} \\
\text { Glucose, } \mathrm{mg} / \mathrm{dl} \\
\text { WBC, } 10^{9} / \mathrm{L} \\
\text { Hemoglobin, g/dl } \\
\text { Platelet, } 10^{9} / \mathrm{L} \\
\text { PT, second }\end{array}$ & $\begin{array}{l}22(19-25) \\
12(10-13) \\
0.8(0.6-1) \\
99(88-115) \\
9.1(6.3-12.1) \\
10.1(8.9-11.6) \\
159(107-227) \\
13.4(12.4-14.8)\end{array}$ & $\begin{array}{l}21(18-24) \\
12(11-14) \\
0.9(0.7-1.3) \\
107(90-125.5) \\
9.2(6.3-13.2) \\
10.1(8.5-12.1) \\
136(84-198) \\
14(12.9-14.9)\end{array}$ & $\begin{array}{l}20(16-23) \\
14(12-16) \\
0.8(0.6-1.3) \\
107(88-127) \\
9.1(5.9-13.1) \\
10.4(8.8-12.3) \\
132(70-201) \\
14.5(12.8-17.8)\end{array}$ & $\begin{array}{l}<0.001 \\
<0.001 \\
<0.001 \\
<0.001 \\
0.808 \\
0.275 \\
<0.001 \\
<0.001\end{array}$ \\
\hline $\begin{array}{l}\text { Comorbidities, } \mathrm{n} \% \\
\text { Congestive heart failure } \\
\text { Atrial fibrillation } \\
\text { Renal disease } \\
\text { Liver disease } \\
\text { Respiratory failure } \\
\text { Malignancy } \\
\text { Sepsis }\end{array}$ & $\begin{array}{l}37(8.6) \\
63(14.6) \\
27(6.3) \\
94(21.8) \\
238(55.1) \\
43(10) \\
97(22.5)\end{array}$ & $\begin{array}{l}36(8.3) \\
75(17.4) \\
27(6.3) \\
18 \mid(4 I .9) \\
209(48.4) \\
53(12.3) \\
98(22.7)\end{array}$ & $\begin{array}{l}22(5.1) \\
53(12.3) \\
29(6.7) \\
195(45.1) \\
223(51.6) \\
44(10.2) \\
140(32.4)\end{array}$ & $\begin{array}{l}0.091 \\
0.107 \\
0.95 \\
<0.001 \\
0.142 \\
0.483 \\
<0.001\end{array}$ \\
\hline $\begin{array}{l}\text { Scoring systems } \\
\text { SOFA } \\
\text { SAPS-II }\end{array}$ & $\begin{array}{l}5(3-7) \\
32(26-4 I)\end{array}$ & $\begin{array}{l}6(4-9) \\
36(28-46)\end{array}$ & $\begin{array}{l}6(3-10) \\
37(26-49)\end{array}$ & $\begin{array}{l}<0.001 \\
<0.001\end{array}$ \\
\hline $\begin{array}{l}\text { Vasoactive drug use, n\% } \\
\text { Length of ICU stay, days } \\
\text { 30-day mortality, n(\%) }\end{array}$ & $\begin{array}{l}164(38) \\
5.6(3.0-10.6) \\
35(8.1)\end{array}$ & $\begin{array}{l}167(38.7) \\
5.1(3-10) \\
71(16.4)\end{array}$ & $\begin{array}{l}175(40.5) \\
5.1(3-10) \\
117(21.1)\end{array}$ & $\begin{array}{l}0.73 \\
0.611 \\
<0.001\end{array}$ \\
\hline
\end{tabular}

Abbreviations: AUD, alcohol use disorder; ICU, intensive care unit; SBP, systolic blood pressure; WBC, white blood cell; PT, prothrombin time; SOFA, sequential organ failure assessment; SAPS II, simplified acute physiology score II.

and in the Methods section. Based on the univariate regression model, the third lactate tertile increased the risk of 30day mortality ( $\mathrm{OR}=4.2,95 \% \mathrm{CI}$ : $2.8-6.3)$.

Based on model I, OR $(95 \% \mathrm{CI})$ of lactate was $\geq 2$ when compared to the reference levels $(<1.3)$ was 4.6 (3.0-7.0) for 30-day mortality. With regard to model II, the third lactate tertile remained a statistically significant risk factor for 30-day all-cause mortality after the adjustment of variables $(\mathrm{OR}=2.7,95 \% \mathrm{CI}: 1.7-4.4)$.

\section{Prediction of Mortality}

ROC curves were performed to further confirm the potential prognosis value of lactate using the indicated variable (lactate, SOFA and SAPS-II) in Figure 2. The AUCs for 


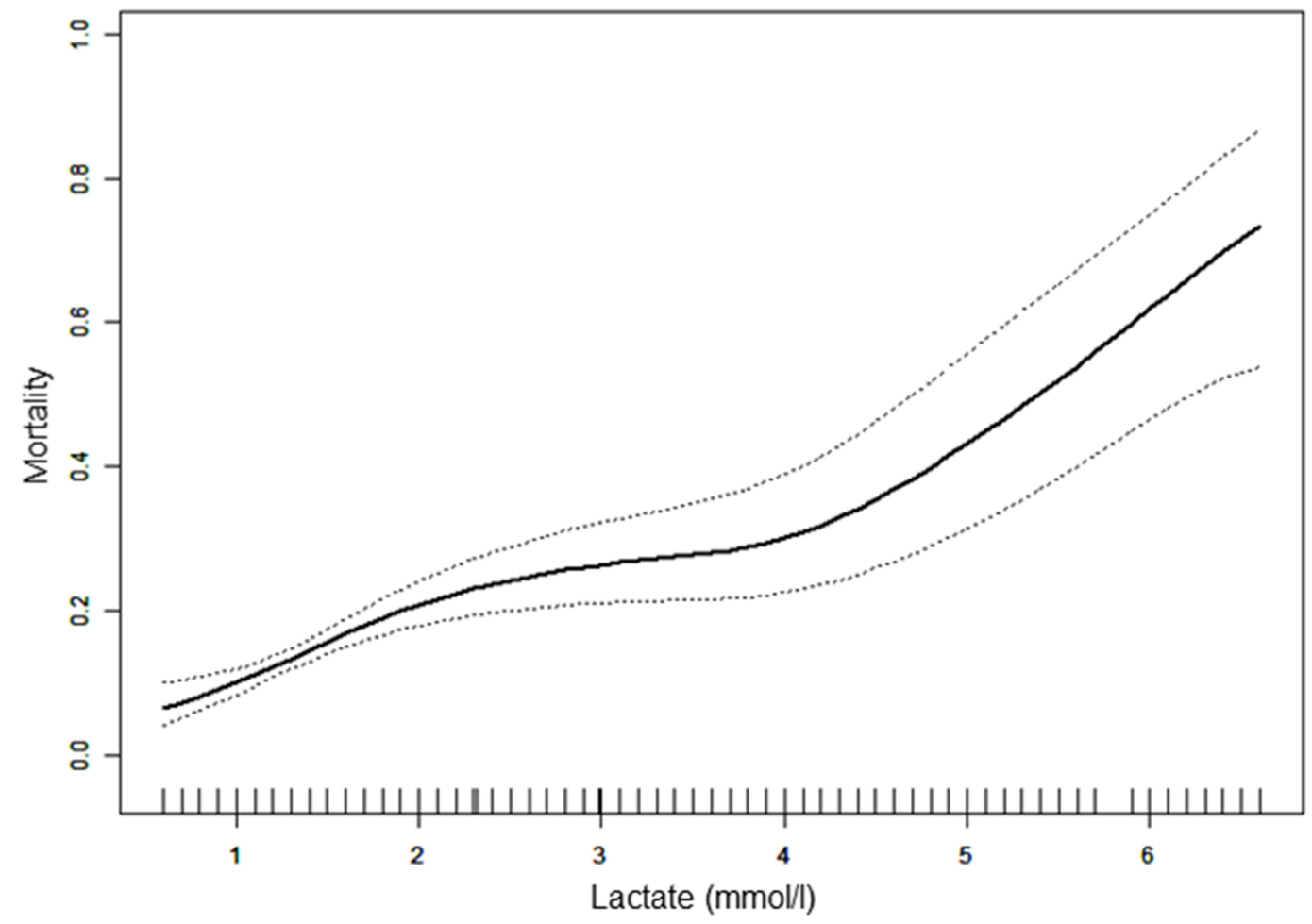

Figure I The relationship between lactate and 30-day mortality in critically ill patients with AUD. The dotted lines on both sides represent $95 \%$ confidence interval.

lactate, SOFA and SAPS-II were 0.672, 0.741, and 0.788, respectively. The AUC of the lactate was lower than these classical scoring systems $(\mathrm{p}<0.01)$.

\section{Subgroup Analysis}

The relationship between 30-day mortality and lactate tertiles in different subgroups is shown in Table 4. In most subgroup, no obvious interaction was observed. But increased risk of 30day all-cause mortality was observed in patients with liver disease.

\section{Discussion}

In the present study, we evaluated the ability of lactate to predict mortality in a cohort of critically ill patients with AUD admitted to ICU. We observed a significant positive correlation between lactate levels and mortality in critically ill patients with AUD. Although the predictive value of lactate was not as good as that of SOFA or SAPS-II, it exhibited a certain predictive performance as an easily available and cheap laboratory parameter.

Table 3 The Association Between Lactate and 30-Day Mortality

\begin{tabular}{|c|c|c|c|c|c|c|}
\hline \multirow[t]{2}{*}{ Lactate } & \multicolumn{2}{|c|}{ Non-Adjusted } & \multicolumn{2}{|l|}{ Model I } & \multicolumn{2}{|l|}{ Model II } \\
\hline & \multicolumn{2}{|c|}{ OR (95\% Cls) P value } & \multicolumn{2}{|c|}{ OR (95\% Cls) P value } & OR (95\% Cls) & $P$ value \\
\hline Tertile I & I.0 (ref) & & I.0 (ref) & & I.0 (ref) & \\
\hline Tertile 2 & $2.2(1.5,3.4)$ & $<0.001$ & $2.2(1.4,3.4)$ & $<0.001$ & $1.6(1.0,2.6)$ & 0.042 \\
\hline Tertile 3 & $4.2(2.8,6.3)$ & $<0.001$ & $4.6(3.0,7.0)$ & $<0.001$ & $2.7(1.7,4.4)$ & $<0.001$ \\
\hline Continuous & $1.6(1.5,1.8)$ & $<0.001$ & $1.7(1.5,1.9)$ & $<0.001$ & $1.4(1.2,1.6)$ & $<0.001$ \\
\hline
\end{tabular}

Notes: a: model I covariates were adjusted for age, sex and ethnicity. b: model II covariates were adjusted for age, sex, ethnicity, SOFA, SAPS-II, liver disease, renal disease, atrial fibrillation, respiratory failure, sepsis, anion gap, creatine, hemoglobin, platelet, bicarbonate, WBC, PT, systolic blood pressure, respiratory rate and vasoactive drug use.

Abbreviations: $\mathrm{OR}$, odds ratio; $\mathrm{Cl}$, confidence interval. 


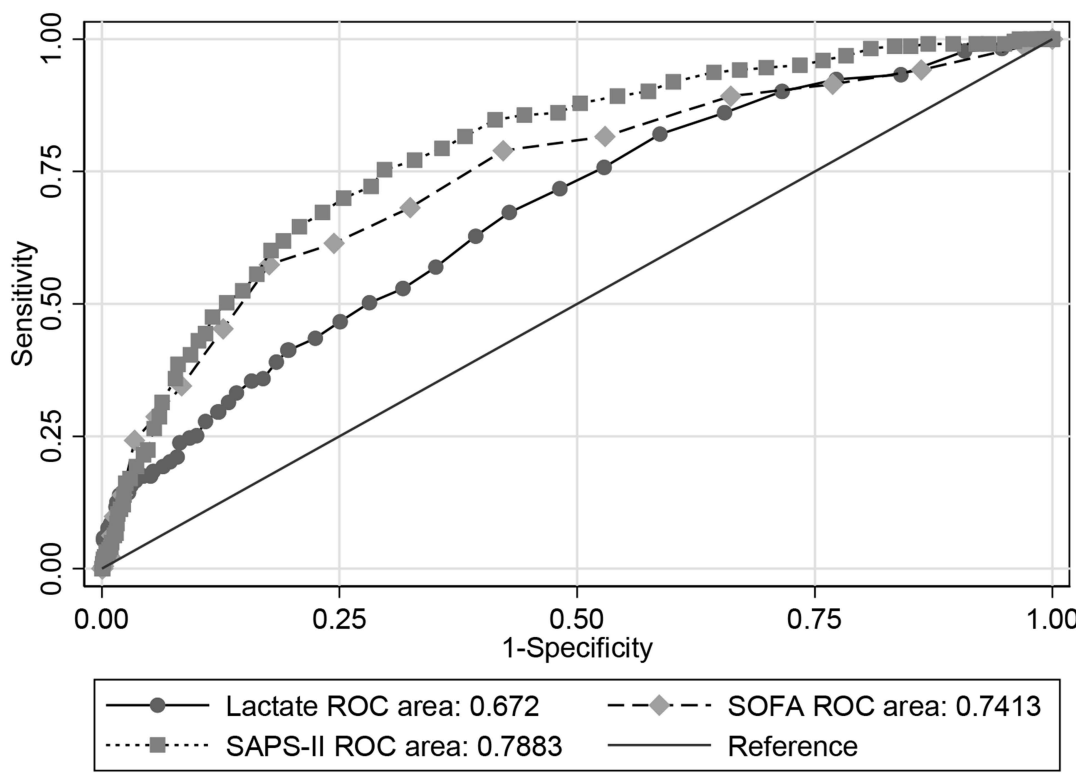

Figure 2 ROC curves for the prediction of mortality in critically ill patients with AUD. The area under curve of lactate, SOFA and SAPS-II were $0.672,0.74$ I 3 , and 0.7883 respectively.

Abbreviations: SOFA, sequential organ failure assessment; SAPS-II, simplified acute physiology score II.

Alcohol consumption causes damage to various organs and systems. The mechanisms of alcohol-related organ injury, which mainly include alcohol metabolism, oxidative stress, inflammation, dysregulation of lipid metabolism, signal transduction pathways, have not been fully understood. ${ }^{14-16}$ Alcohol abuse is common among 10\% of patients admitted to ICU. ${ }^{17}$ In some hospitals in the USA, alcohol abuse is responsible for up to $40 \%$ of all admissions. ${ }^{8}$ Critically ill patients with AUD have poor prognosis, and they face a high economic burden associated with the disease. ${ }^{18}$ Therefore, identifying a simple and accessible prognosis predictor could facilitate the identification of high-risk critically ill patients with AUD and promote timely adoption of appropriate interventions. However, studies analyzing specific prognostic markers for critically ill patients with AUD are limited.

Lactate has been comprehensively studied as a prognostic biomarker for several diseases, including sepsis, ${ }^{19}$ trauma, ${ }^{20}$ cardiac diseases,${ }^{21}$ and gastrointestinal diseases. ${ }^{22}$ High lactate levels has been demonstrated to be independently associated with mortality in critically ill patients or patients in the emergency department. $^{23-26}$ Lactate level is generally low when lactate clearance from blood and production are balanced under normal conditions in healthy individuals. Increase in lactate level could be caused by increased production, decreased clearance or both. Lactic acidosis is prevalent in ICU patients, and it can be classified into two subtypes. Type A, which is frequently observed in critically ill patients, is associated with hypoperfusion or tissue hypoxia that is a leading cause of increased lactate levels. ${ }^{27}$ Type B is generally not associated with oxygen consumption and it includes the conditions influencing the production and elimination of lactate. Examples of type B lactic acidosis include liver disease, renal failure, malignancy, medications (metformin, epinephrine), thiamine deficiency, and ethanol intoxication. ${ }^{12}$

Alcohol consumption can induce metabolic acidosis, which increases lactate level mainly due to its metabolic effects by increasing the increase of the NADH/NAD ratio and favor the metabolism of pyruvate to lactate. ${ }^{27}$ Other causes, such as thiamine deficiency, sepsis, and other underlying comorbidities could also result in high lactate levels. Thus, a single measurement of lactate concentration is difficult to interpret, especially in patients with alcohol consumption. These results cast doubts about the reliability of lactate level as a useful biomarker to risk-stratify critically ill patients with AUD. A few studies have addressed the effect of ethanol on prognostic value of lactate and base deficit in trauma patients. Previous studies by Zehtabchi et $\mathrm{al}^{28}$ and Dunne et $\mathrm{al}^{29}$ demonstrated that ethanol did not impair the prognosis accuracy of admission lactate. However, a study conducted by Gustafson et al have found that the presence of ethanol exposure 
Table 4 Subgroup Analysis of the Associations Between Lactate and 30-Day All-Cause Mortality

\begin{tabular}{|c|c|c|c|c|c|}
\hline & $\mathbf{N}$ & Lactate<1.3 (ref) & $1.3 \leq$ Lactate $<2$ OR $(95 \%$ Cls $)$ & Lactate $\geq 2$ OR (95\% Cls) & $P$ for Interaction \\
\hline Gender & & & & & 0.456 \\
\hline $\mathrm{F}$ & 320 & Ref & $3.5(1.3,9.4)$ & $6.3(2.3,17.1)$ & \\
\hline$M$ & 976 & Ref & $1.7(1.0,3.0)$ & $3.1(2.9,5.2)$ & \\
\hline Ethnicity & & & & & 0.622 \\
\hline White & 924 & Ref & $2.1(1.2,3.5)$ & $3.2(1.9,5.4)$ & \\
\hline Black & 92 & Ref & $0.1(0.0,3.6)$ & $2.8(0.2,48.4)$ & \\
\hline Other & 280 & Ref & $2.0(0.7,5.5)$ & $5.0(2.0,12.8)$ & \\
\hline $\mathrm{CHF}$ & & & & & 0.408 \\
\hline No & $120 \mid$ & Ref & $2.1(1.3,3.4)$ & $3.7(2.3,5.8)$ & \\
\hline Yes & 95 & Ref & $1.7(0.3,8.3)$ & $\mathrm{I} .4(0.2,7.9)$ & \\
\hline $\mathrm{AF}$ & & & & & 0.439 \\
\hline No & 1105 & Ref & $1.9(1.1,3.2)$ & $3.8(2.3,6.3)$ & \\
\hline Yes & 191 & Ref & $2.0(0.8,5.1)$ & I.8 $(0.7,5.1)$ & \\
\hline Renal disease & & & & & 0.628 \\
\hline No & 1213 & Ref & $2.0(1.2,3.3)$ & $3.5(2.2,5.6)$ & \\
\hline Yes & 83 & Ref & $2.4(0.5,12.3)$ & $3.9(0.8,18.7)$ & \\
\hline Liver disease & & & & & 0.019 \\
\hline No & 826 & Ref & I.I $(0.6,2.1)$ & $2.1(1.2,3.8)$ & \\
\hline Yes & 470 & Ref & $4.3(2.0,9.6)$ & $6.7(3.1,14.6)$ & \\
\hline Malignancy & & & & & 0.493 \\
\hline No & 1156 & Ref & $2.1(1.3,3.5)$ & $3.8(2.3,6.2)$ & \\
\hline Yes & 140 & Ref & $1.2(0.3,4.6)$ & $2.0(0.6,7.2)$ & \\
\hline Respiratory failure & & & & & 0.493 \\
\hline No & 626 & Ref & $1.5(0.7,3.2)$ & $2.8(1.3,5.8)$ & \\
\hline Yes & 670 & Ref & $2.2(1.3,3.9)$ & $3.7(2.2,6.5)$ & \\
\hline Sepsis & & & & & 0.098 \\
\hline No & 961 & Ref & I.7 $(1.0,2.9)$ & $3.0(1.8,5.2)$ & \\
\hline Yes & 335 & Ref & $2.6(1.1,6.2)$ & $4.0(1.8,9.0)$ & \\
\hline Vasoactive drug & & & & & 0.275 \\
\hline No & 790 & Ref & $3.1(1.5,6.8)$ & $4.5(2.1,9.5)$ & \\
\hline Yes & 506 & Ref & $1.3(0.7,2.4)$ & $3.0(1.7,5.2)$ & \\
\hline
\end{tabular}

Abbreviations: OR, odds ratio; $\mathrm{Cl}$, confidence interval.

confounds the prognostic value of lactate. ${ }^{30}$ These studies were limited to trauma patients. Our study was conducted in a large mixed cohort of critically ill patients with AUD. The results of the present study are consistent with the findings of Zehtabchi et al and Dunne et al. In spite of the effect of alcohol in promoting lactate production, our results have demonstrated that blood lactate levels can be a key independent predictor of mortality among critically ill patients with AUD.

\section{Strengths and Limitations of the Study}

A large sample size is one advantage of this study. Limitations of the present study included the following. First, the study was a single-center retrospective analysis; therefore, data were subject to selection biases. Second, we only measured lactate levels in patients upon admission to ICU and did not evaluate dynamic changes during the ICU stay. Third, although we used a multivariate regression 
model to control bias, transaminase and bilirubin had to be excluded from our analyses because the data was unavailable. Also, there could have been other known and unknown confounding factors. Therefore, multicenter prospective studies should be conducted to verify our findings.

\section{Conclusions}

The present study revealed that blood lactate levels of critically ill patients with AUD at admission were significantly correlated with mortality. Blood lactate level could be a potential novel independent predictor of mortality in critically ill patients with AUD. However, large, multicenter prospective studies should be conducted to verify the clinical significance of lactate.

\section{Ethics Statement}

The MIMIC-III database has received ethical approval from the institutional review boards (IRBs) at Beth Israel Deaconess Medical Center and Massachusetts Institute of Technology. Requirement for individual patient consent was waived Because the study did not impact clinical care and all protected health information was deidentified.

\section{Disclosure}

The authors declare no conflicts of interest.

\section{References}

1. Griswold MG, Fullman N, Hawley C; Collaborators GBDA. Alcohol use and burden for 195 countries and territories, 1990-2016: a systematic analysis for the Global Burden of Disease Study 2016. Lancet. 2018;392(10152):1015-1035. doi:10.1016/S0140-6736(18) 31310-2.

2. Buchanan R, Sinclair JMA. Alcohol use disorder and the liver. Addiction. 2020. doi:10.1111/add.15204

3. Day E, Rudd JHF. Alcohol use disorders and the heart. Addiction. 2019;114(9):1670-1678. doi:10.1111/add.14703

4. Schuckit MA. Alcohol-use disorders. Lancet. 2009;373 (9662):492-501. doi:10.1016/s0140-6736(09)60009-x

5. Dguzeh U, Haddad NC, Smith KTS, et al. Alcoholism: a multi-systemic cellular insult to organs. Int J Env Res Public Health. 2018;15(6). doi:10.3390/ijerph15061083

6. Shield KD, Rehm J. Alcohol and the global burden of disease. Lancet. 2019;393(10189):2390. doi:10.1016/S0140-6736(19)30726-3

7. de Wit M, Jones DG, Sessler CN, Zilberberg MD, Weaver MF. Alcohol-use disorders in the critically ill patient. Chest. 2010;138 (4):994-1003. doi:10.1378/chest.09-1425

8. Moss M, Burnham EL. Alcohol abuse in the critically ill patient. Lancet. 2006;368(9554):2231-2242. doi:10.1016/S0140-6736(06) 69490-7

9. Aduen J, Bernstein WK, Khastgir T, et al. The use and clinical importance of a substrate-specific electrode for rapid determination of blood lactate concentrations. JAMA. 1994;272(21):1678-1685. doi:10.1001/jama.1994.03520210062033
10. Nichol AD, Egi M, Pettila V, et al. Relative hyperlactatemia and hospital mortality in critically ill patients: a retrospective multi-centre study. Crit Care. 2010;14(1):R25. doi:10.1186/cc8888

11. Dezman ZD, Comer AC, Narayan M, Scalea TM, Hirshon JM, Smith GS. Alcohol consumption decreases lactate clearance in acutely injured patients. Injury. 2016;47(9):1908-1912. doi:10.1016/ j.injury.2016.03.007

12. Andersen LW, Mackenhauer J, Roberts JC, Berg KM, Cocchi MN, Donnino MW. Etiology and therapeutic approach to elevated lactate levels. Mayo Clin Proc. 2013;88(10):1127-1140. doi:10.1016/j. mayocp.2013.06.012

13. Johnson AE, Pollard TJ, Shen L, et al. MIMIC-III, a freely accessible critical care database. Sci Data. 2016;3:160035. doi:10.1038/ sdata.2016.35

14. Achur RN, Freeman WM, Vrana KE. Circulating cytokines as biomarkers of alcohol abuse and alcoholism. $J$ Neuroimmune Pharmacol. 2010;5(1):83-91. doi:10.1007/s11481-009-9185-z

15. Rehm J. The risks associated with alcohol use and alcoholism. Alcohol Res Health. 2011;34(2):135-143.

16. Osna NA, Kharbanda KK. Multi-organ alcohol-related damage: mechanisms and treatment. Biomolecules. 2016;6(2). doi:10.3390/ biom6020020.

17. Halpern NA, Bettes L, Greenstein R. Federal and nationwide intensive care units and healthcare costs: 1986-1992. Crit Care Med. 1994;22(12):2001-2007.

18. Rehm J, Mathers C, Popova S, Thavorncharoensap M, Teerawattananon Y, Patra J. Global burden of disease and injury and economic cost attributable to alcohol use and alcohol-use disorders. Lancet. 2009;373(9682):2223-2233. doi:10.1016/S01406736(09)60746-7

19. Mikkelsen ME, Miltiades AN, Gaieski DF, et al. Serum lactate is associated with mortality in severe sepsis independent of organ failure and shock. Crit Care Med. 2009;37(5):1670-1677. doi:10.1097/ CCM.0b013e31819fcf68

20. Freitas AD, Franzon O. Lactate as predictor of mortality in polytrauma. Arq Bras Cir Dig. 2015;28(3):163-166. doi:10.1590/ S0102-67202015000300004

21. Gjesdal G, Braun OO, Smith JG, Schersten F, Tyden P. Blood lactate is a predictor of short-term mortality in patients with myocardial infarction complicated by heart failure but without cardiogenic shock. BMC Cardiovasc Disord. 2018;18(1):8. doi:10.1186/s12872018-0744-1

22. Gulen M, Satar S, Tas A, Avci A, Nazik H, Toptas Firat B. Lactate level predicts mortality in patients with upper gastrointestinal bleeding. Gastroenterol Res Pract. 2019;2019:5048078. doi: $10.1155 / 2019 / 5048078$

23. Bou Chebl R, El Khuri C, Shami A, et al. Serum lactate is an independent predictor of hospital mortality in critically ill patients in the emergency department: a retrospective study. Scand J Trauma Resusc Emerg Med. 2017;25(1):69. doi:10.1186/ s13049-017-0415-8

24. Chebl RB, Tamim H, Dagher GA, Sadat M, Enezi FA, Arabi YM. Serum lactate as an independent predictor of in-hospital mortality in intensive care patients. $J$ Intensive Care Med. 2020;35 (11):1257-1264. doi:10.1177/0885066619854355

25. Park YJ, Kim DH, Kim SC, et al. Serum lactate upon emergency department arrival as a predictor of 30-day in-hospital mortality in an unselected population. PLoS One. 2018;13(1):e190519. doi:10.1371/journal.pone.0190519

26. Hayashi Y, Endoh H, Kamimura N, Tamakawa T, Nitta M. Lactate indices as predictors of in-hospital mortality or 90-day survival after admission to an intensive care unit in unselected critically ill patients. PLoS One. 2020;15(3):e229135. doi:10.1371/journal.pone.0229135

27. Luft FC. Lactic acidosis update for critical care clinicians. J Am Soc Nephrol. 2001;12(Suppl 17):S15-9. doi:10.1681/ASN. V12suppl_1s15 
28. Zehtabchi S. Ethanol and illicit drugs do not affect the diagnostic utility of base deficit and lactate in differentiating minor from major injury in trauma patients. Acad Emerg Med. 2004;11(10):1014-1020. doi:10.1197/j.aem.2004.06.008

29. Dunne JR, Tracy JK, Scalea TM, Napolitano LM. Lactate and base deficit in trauma: does alcohol or drug use impair their predictive accuracy? J Trauma. 2005;58(5):959-966. doi:10.1097/01. ta.0000158508.84009.49
30. Gustafson ML, Hollosi S, Chumbe JT, Samanta D, Modak A, Bethea A. The effect of ethanol on lactate and base deficit as predictors of morbidity and mortality in trauma. Am J Emerg Med. 2015;33(5):607-613. doi:10.1016/j.ajem.2015.01.030

\section{Publish your work in this journal}

The International Journal of General Medicine is an international, peer-reviewed open-access journal that focuses on general and internal medicine, pathogenesis, epidemiology, diagnosis, monitoring and treatment protocols. The journal is characterized by the rapid reporting of reviews, original research and clinical studies across all disease areas. The manuscript management system is completely online and includes a very quick and fair peer-review system, which is all easy to use. Visit http://www.dovepress.com/ testimonials.php to read real quotes from published authors.

Submit your manuscript here: https://www.dovepress.com/international-journal-of-general-medicine-journal 